\title{
Team-based Classroom Pedagogy Reframed: The Student Perspective
}

Jennifer L. Schultz, Metropolitan State University, USA

Joel R. Wilson, Metropolitan State University, USA

Kenneth C. Hess, Metropolitan State University, USA

\begin{abstract}
Postsecondary learning environments often utilize team-based pedagogical practices to challenge and support student learning outcomes. This manuscript presents the findings of a qualitative research study that analyzed the viewpoints and perceptions of group or team-based projects among undergraduate business students. Results identified five pro-team thematic perspectives of team learners' views including better deliverables, increased ideas, improved learning experiences, reduced workload, and collective security. Responses from students who preferred to work autonomously resulted in three themes centered on self-sufficiency, social loafing, and schedule challenges. Two situational student responses were identified regarding how and why faculty should utilize group and team projects in consideration of individual efficiency and assignment objectives and outcomes conflicts. This study concludes with research-based recommendations for teaching, learning, and further research.
\end{abstract}

Keywords: group, team, collaborative learning

\section{INTRODUCTION}

$\mathcal{G}$ mployers are in need of employees who have the skills to work on and lead teams. Generally, in most circumstances, groups outperform individuals (Johnson \& Johnson, 1989; Slavin 1983) and even recent graduates hail the need for teamwork skills (Hansen, 2006). So, it would appear congruent that the postsecondary business curricula would emphasize group and team projects in most coursework. Bormann Young and Henquinet (2000) emphasize the effective use of groups by faculty as the key to linking the classroom and work experiences effectively, however comparatively little college-level group learning research exists (Slavin, 1990). Even less is known about the student viewpoint of working and learning in groups and teams in the collegiate classroom.

On one hand, team-based assignments incorporate skills necessary for employability like collaboration, problem solving, communication, and shared vision; on the other hand, many students are burdened with a history of weak performing teams and academic frustration rooted in team-based assignments. Business faculty must decide for themselves when and how to use team-based assignments in their classes and the subsequent student learning and opinions of those decisions.

The purpose of this paper is to provide postsecondary student insights regarding team-based assignments. The voices represented are from students enrolled in a Principles of Supervisory Management course at a large public research university during the spring semester of 2008. This manuscript presents the initial findings of a research study that looked at business education students' perspectives of working in teams.

\section{METHOD}

The sample for this study was collected in January 2008 from an upper-division undergraduate work and human resource education lecture section course at a major Midwestern research institution. The participants were students majoring in business related education curriculum. This course initially enrolled 35 students, 30 students attended the first class meeting and subsequently finished the course. 
Students were recruited to participate voluntarily in-class; they were given participation points for responding to weekly questions regarding a variety of student views and opinions. The faculty member provided all informed consent information verbally and in writing to all students and verified that participation was voluntary and they were not required to participate in the research study. She communicated that student responses would be confidential, but not anonymous, so that students could be identified to receive participation points for the assignment. Students were informed that they would not be individually identified in the presentation of results. Students completed the weekly questions during class on paper provided by the faculty member.

The cumulative data set for this study was the written student responses from the open-ended question: Do you prefer to work alone or in a group/team? Why?

The students' responses were read and reread by the authors to gain a general understanding of the viewpoints. They were then categorized into 26 unique meaning units. Then, rich, unique, or poignant responses were noted; five team preferred, four autonomy preferred, two overlapping (increased ideas and social loafers), and two unique situational responses emerged. The emergent categorical team preferred themes were as follows: (a) better deliverables, (b) increased ideas, (c) improved learning experience, (d) reduced workload, and (e) collective security. The surfacing autonomy preferred themes included: (a) self-sufficiency, (b) social loafing, (c) schedule challenges, and (d) work and school team differentiation. The situational themes were related to individual efficiency, and conflicting assignment outcomes and objectives. This manuscript develops these themes using the student voice via noteworthy phrases and quotes related to the theme units to develop the meanings and then finally a critical discourse for faculty consideration is presented along with notes for discussion of the research-based conclusions and recommendations for teaching, learning, and future research.

\section{RESULTS}

Of the 30 students enrolled in the class, 28 completed and submitted legible consent forms. Of the 28 students who were present during data collection and responded in-class to the assignment, 27 had completed informed consent forms. Thus, the actual response rate for this study was $96.4 \%$, reflecting the 28 students who completed the assignment out of the 27 who agreed to participate in the study. The question, "Do you prefer to work alone or in a group/team? Why?" yielded 27 student responses. The responses were, 11 (40.7\%) who prefer to work in a group or team, while $9(33.3 \%)$ replied that they preferred to work alone. Seven students (25.9\%) responded that their work preference was not categorically, yes or no, but rather situational and specific examples were provided. Clearly, the student view, instructor, assignment objectives and outcomes, along with team itself are all variables in determining student positions on affection towards team-based learning. In an effort to better understand the students' perspective we first analyzed the responses provided by each respondent group independently.

\section{PREFER TEAMWORK}

The responses provided by the students that preferred to work in teams were read, reread, analyzed, and grouped by similar themes. The results developed five key theme areas that richly explained reasons and rationalizations for students' preference to work in teams. Please note that two of the eleven students who preferred group-work also contradicted their positions with several negative outcomes for working in groups.

The five key student themes identified in support of team-based learning included the following: (a) better deliverables, (b) increased ideas, (c) improved learning experience, (d) reduced workload, and (e) collective security. Woven among the first three themes was an overarching belief that the diversity of ideas offered through a team-based assignment could not be replicated by each individual working alone. In fact, the student responses pointed to the team dynamic itself as transforming initial ideas into new and improved ideas throughout the teambased learning experience. This suggests that the team dynamic and work by definition and function alone generates ideas and solutions that would otherwise be missed by solitary learners.

The following is an overview of each of the five themes identified by students who report positive perceptions of team-based learning. Each theme was developed and described focused on student voice and the key thoughts generated by the student comments. 


\section{Better Deliverables}

The multiple perspectives inherent in teams often brings broadened and unique expertise, coupled with higher level critical thinking, all resulting in a better end product. Quoting a student on the added perspective, "I like the different opinions and expertise everyone brings to a group." Another student shared, "you can find flaws in the design and other problems more effectively in a group" while still another view was specific to the final deliverable, "often a team can build upon another's ideas and the end product is much more deep."

\section{Increased Ideas}

A team, by definition is more than one person and therefore, not only does this construct bring differing individual opinions and viewpoints, but it can also result in the generation of new and divergent ideas. Student comments elucidated the increased ideas. The following is what students had to say about the additional ideas, "working in teams allows for many more ideas and opinions to be thrown out in the open." Another student writes about the socializing qualities of idea generation, "I prefer to work in a group because with everyone brainstorming the outcome is much more diverse and detailed. Plus, then you get to chit - chat!" Again, the team is seen as a facilitator and catalyst for idea generation, specifically in a student lens, "I like the variety of opinions, thoughts and different strategies working in group settings towards the completion of a goal or task."

\section{Improved Learning}

According to students, teamwork supports peer learning both cognitive and socially, "working in groups can build relationships and allows people to learn from each other and collaborate all of your strengths." When working in a team, students are also able to see multiple perspective in very real and tangible ways, specifically, "when working as part of a team, I am able to gain insight into others' beliefs, strengths, ideas, etc." and report that their learning is enhanced, "I like working with other minds. I feel that I learn more when I work in group."

\section{Reduced Workload}

The team provides a vehicle, usually through additional hands and delegation, that permits for the completion of large projects in a more effective, efficient, timely and manageable manner. Some students see delegation as a driver, "more can be accomplished due to delegation" other see the collectivism, "having one or more people help work on a task helps get it done much quicker than a person could by themselves."

\section{Collective Security}

Students report the team formation to be a main factor in reducing both anxiety and a reduction in stress associated to the complexity of academic projects. Some students see the team as a moderator to overwhelming projects, quoting, "groups make a project seem less intimidating" while others acknowledge the benefit to having informed peers to help guide the outcomes, "it's nice that if you aren't completely sure on an issue or something, it's most likely possible that someone in your group can provide you with that answer."

The above mentioned affirmative team-based themes identified strong student viewpoints in support of team-based assignments. Still, they do not provide a complete picture of the students' perspective. In fact, as previously mentioned, two of the students that identified themselves as preferring to work in teams also indicated that negative aspects often exist. In particular, one negative issue identified was that of "freeloaders" and the concern that some individuals are not doing their fair share. The "freeloader" issue was linked to grading inaccuracy and not receiving "true credit" for work performed. In addition to the freeloader issue, coordination of team member schedules was identified as a significant issue. Interestingly, both of these negatives were themes identified when analyzing the responses of those students that preferred to work independently, and will be addressed in the following section. 


\section{PREFER AUTONOMOUS WORK}

In the analysis of student responses that preferred to work on their own, four key themes were identified. Those themes included the following: (a) grade reciprocity, (b) social loafing, (c) schedule challenges, and (d) work and school team differentiation. The students that preferred to work autonomously did offer two positive aspects of team-based assignments. Interestingly, these positive aspects were identified within the five positive themes presented above, specifically, the increased number of ideas and reduction of workload. Consistent with the analysis of the positive themes, a more meaningful description has been developed for each of the four negative themes and related student quotes have been provided.

\section{Grade Reciprocity}

Students who show a preference towards working alone cite grade reciprocity (self-determination of grades) as a key rationale. For some students the team structure by nature is uncomfortable and vulnerable because students are forced to rely on peers with the end result impacting their individual grade on the assignment and ultimately within the course. Students see the exposure of this arrangement in multiple lenses, "I don't like to be responsible for other people's grade or pay." They are also often plagued by histories of poorly performing team experiences, as reflected in the following quote, "[I prefer] alone, less schedule conflict, responsible for myself. [I] had [a] bad experience w/group last semester."

\section{Social Loafing}

Students refer to social loafing as freeloaders when explaining their aversion to teams describing the behavior and lack of motivation of some members toward team objectives. This inequity of workload distribution and deficiency among peers can prove frustrating and just enough for a student to position themselves in anti-team sentiments. The following quote speaks to this inequality, "I have never been in a group where the work is equal amongst all participants." The inability to positively influence peers leads to frustration, another student writes, "I don't like working in teams because so many people today are so unmotivated that I get frustrated."

\section{Schedule Challenges}

Team-based learning requires students to work both synchronous and asynchronous to achieve successful outcomes. They report a compounding reason for their dislike to teams in the synchronous nature of the work. This is exemplified in student words, "I feel like with busy lives it is very difficult to coordinate times when you are all available for a large amount of time to get together." It is interesting that students point to scheduling conflicts in an era of multiple communication alternatives, where the availability of these tools could virtually eliminate the need for face-to-face team interaction. Why scheduling challenges still exist may be tied to a technology divide amongst group members or it may be as simple as the students' belief that face-to-face interaction is required for team success.

\section{Work and School Team Differentiation}

From the view of the student, work teams and school teams evoke very different responses. Students report a preference to work teams and avoidance to school teams and specifically say, "work teams are better than class teams because people are better compensated for their effort" and "most of the time, I like to work alone, simply for the reason that students are sometimes unreliable and it turns out to be unfair (in a school situation). In a work environment, I like to work in teams because everyone wants to be involved and participate." The students that prefer to work independently provide a solid list of reasons to avoid team-based learning. Consistent with the students that prefer team-based, these students acknowledge that there are positive aspects of group work. The fact that both groups pointed to the opposite perspective leads to the situational response group. 


\section{SITUATIONAL TEAM PERSPECTIVES}

The mere presence of the third "situational" set of respondents elucidates the complexity of the research question, and the desire for participants to contextualize their responses. This tendency to contextualize team-based learning is indicative of the vast number of confounding factors that impact the students' perspective and success in team work. Students who responded in a situational way, often expressed as, "it depends" identified four main themes. Two were discussed above, one team positive (increased ideas) and one autonomous (social loafers), with the remaining two themes grounded in autonomous rationale and centered on individual efficiency and conflicting assignment outcomes and objectives, both unique from themes identified above. Interestingly, both results point to more pragmatic fact type rationales. A brief review of these themes and supporting quotes are provided below.

\section{Individual Efficiency}

Students view working independently to be more efficient when timeline pressure exists. This perspective is exemplified in student voice, "when I'm under pressure to finish something quickly, I prefer working alone. When I'm going about regular work activities, I enjoy group work." Students report the drag that working in a team can have in completing the assignment, "but at times by working in groups will slow some processes down." This student viewpoint suggests experience in team projects that inherently would be best completed independently.

\section{Conflicting Assignment Outcomes and Objectives}

The results of this study found students have an opinion on when team assignments are or are not appropriate. Students specifically identify written work as an example of work more appropriately completed alone. When speaking to this point, "papers - always prefer alone" and "if it's a paper or any other project, I prefer to work by myself just because it's hard to coordinate written work." Clearly the "it depends" group recognizes both positive and negative aspects of group work. This group confirms that one of the strongest aspects of group work "increased number of ideas" is widely accepted. Still, from an overall perspective, the analysis of the "it depends" group suggests a slant towards the negative.

\section{DISCUSSION AND CONCLUSION}

Students report both positive and negative aspects inherent to team-based assignments. As faculty, these positive and negative responses should be considered to have merit and be taken into consideration as assignments, rubrics, and learning outcomes are developed. Through positioning and further research, faculty can better match student team experiences to expected learning outcomes. Faculty as catalyst requires reflective development and ownership of the team-based framework in an effort to reinforce the positive and minimize the negative experiences of team projects for students. In addition, checks and balances should be developed and integrated into team projects to ensure each student is achieving the expected learning outcomes.

The authors recognize the research question itself may be viewed as problematic for many reasons on many levels. The use of prefer can be interpreted as ambiguous, leading, or even creating a biased response among respondents, not to mention that preferences can be significantly influenced by context, social identity, and prior experiences. That being said, the authors are specifically interested in student viewpoints. By using a term that elucidates a perception or preference was of particular interest to the research agenda. The use of the term group/team in the question was to allow students to respond from either experience - that of a group or that of a team. It was thought using both terms would provide for the richest most poignant responses with the intention that further research would focus on one specific term and pedagogical practices unique to either groups or teams.

The terms team and group are often used interchangeable in both work and academic settings, but actually have very different meanings and purposes. According to Katzenbach and Smith (1993) teams are not merely nebulous groups but rather defined by the inclusiveness of the motivating and energizing nature of the label. Groups are defined by the contribution of the individuals while teams are evaluated by the collective deliverables. All teams are groups but all groups are not teams, "a team is more than the sum of its parts" (Katzenbach \& Smith, p. 112). 


\section{Leverage the Positive and Minimize the Negative}

Students identified five positive and six negative team-based themes. The positive themes were (a) better deliverables, (b) increased ideas, (c) improved learning experience, (d) reduced workload, and (e) collective security. The opportunity for instructors is to clearly leverage these positive aspects into the potential group project is the challenge. The negative themes were (a) grade reciprocity, (b) social loafing, (c) scheduling challenges, (d) disconnect between work and school teams, (e) inefficiency of teams, and (f) conflicting assignment outcomes and objectives. The goal for the instructor would be to eliminate or minimize these aspects by design.

To leverage the positive and minimize the negative aspects of team-based learning faculty should integrate checks and balances into the team assignment. The checks and balances serve both as a roadmap for the students as well as creates an additional learning platform for the instructor. We propose three strategies as an initial "checks and balances" starting point for instructor consideration. These initial strategies are the team charter, peer evaluations, and designated in-class team time.

\section{Team Charter}

The primary purpose of the team charter is to clarify team goals and objectives as well as assign clear expectations to team member accountability. Implementing a team charter can be managed in a number of ways, and the approach chosen will be based on the assignment itself and specific learning objectives tied to the charter. Instructor involvement in charter development should be predicated on the intended learning outcomes. Instructors may consider references to the charter in the assignment outline including how the charter may be used by team members as well as the instructor.

\section{Peer Evaluation}

Including a peer evaluation into team assignments is an essential feedback mechanism for individual students, and an additional communication mode for faculty. It also provides the student evaluator an opportunity to look at performance from an alternate perspective. The method employed by the instructor should take into consideration anonymity and relative accuracy of the evaluation. We recommend that a peer evaluation form be included in the assignment outline. The form itself should include clear rubrics and a written section that requires the evaluator to articulate strengths and opportunities. The actual assignment of points by the student evaluator is another subject for discussion. An alternative may be the evaluator to simply choose descriptions that best fit the performance. This information along with the written strengths and weaknesses could then be used by the instructor to assign grades.

\section{Designated Class Time}

Allotted class time for team projects highlights the importance of the assignment as well as provides the instructor the opportunity to observe group dynamics. More importantly, by providing class time, team interaction is virtually guaranteed. This is especially relevant in many non-traditional academic settings where significant outside responsibilities like work and family impact a greater number of students. Students with complex personal circumstances can be at a disadvantage when significant group time is required outside of the classroom.

\section{Checks and Balances Overview}

Table 1 identifies the recommended checks and balances and suggested strategies that either reinforce the positive aspects of team-based learning or minimize the negative aspects of team-based learning. The table is not intended to serve as an exhaustive list but rather a starting point for the integration of strategic classroom based team assignment implementation. 


\begin{tabular}{|c|c|c|c|}
\hline $\begin{array}{l}\text { Positive } \\
\text { Themes } \\
\end{array}$ & $\begin{array}{c}\text { Solution \#1: } \\
\text { Team Charters } \\
\end{array}$ & $\begin{array}{c}\text { Solution \#2: } \\
\text { Peer Evaluations } \\
\end{array}$ & $\begin{array}{c}\text { Solution \#3: } \\
\text { Designated In-class Time } \\
\end{array}$ \\
\hline $\begin{array}{l}\text { Better } \\
\text { deliverables }\end{array}$ & $\begin{array}{l}\text { Team members clearly define } \\
\text { assignment outcome expectations } \\
\text { on grade, format, timing, etc. }\end{array}$ & $\begin{array}{l}\text { Clear documentation of } \\
\text { evaluation criteria provides } \\
\text { guidance on performance } \\
\text { expectations. }\end{array}$ & $\begin{array}{l}\text { Increases opportunity for group } \\
\text { interaction. } \\
\text { Allows for instructor interaction } \\
\text { with individual groups. }\end{array}$ \\
\hline Increased ideas & $\begin{array}{l}\text { Group engagement procedures } \\
\text { allow for balanced input by each } \\
\text { team member. }\end{array}$ & $\begin{array}{l}\text { Specific expectation established } \\
\text { for the contribution of ideas. }\end{array}$ & $\begin{array}{l}\text { Allows faculty to refocus } \\
\text { wayward discussions }\end{array}$ \\
\hline $\begin{array}{l}\text { Improved } \\
\text { learning } \\
\text { experience }\end{array}$ & $\begin{array}{l}\text { Guidance in all areas of team } \\
\text { interaction improves team } \\
\text { function. } \\
\text { Member roles and responsibilities } \\
\text { are clearly defined upfront. }\end{array}$ & $\begin{array}{l}\text { Provides outlet for both positive } \\
\text { and negative feedback. } \\
\text { Increases performance } \\
\text { perspective using peer evaluator } \\
\text { role. } \\
\text { Increased team skills gained by } \\
\text { peer evaluation input. }\end{array}$ & $\begin{array}{l}\text { Lessens stress by reducing the } \\
\text { number of outside classroom } \\
\text { meetings. }\end{array}$ \\
\hline $\begin{array}{l}\text { Reduced } \\
\text { workload }\end{array}$ & $\begin{array}{l}\text { Establishes clear expectations and } \\
\text { agreement in terms of distribution } \\
\text { of duties. }\end{array}$ & $\begin{array}{l}\text { Encourages contribution from all } \\
\text { team members. }\end{array}$ & $\begin{array}{l}\text { Reduces outside of class time } \\
\text { requirements. }\end{array}$ \\
\hline $\begin{array}{l}\text { Collective } \\
\text { security }\end{array}$ & $\begin{array}{l}\text { Clarity limits surprises at the end } \\
\text { of project. }\end{array}$ & & Allows for instructor questions. \\
\hline $\begin{array}{c}\text { Negative } \\
\text { Themes }\end{array}$ & $\begin{array}{c}\text { Solution \#1: } \\
\text { Team Charters }\end{array}$ & $\begin{array}{c}\text { Solution \#2: } \\
\text { Peer Evaluations }\end{array}$ & $\begin{array}{c}\text { Solution \#3: } \\
\text { Designated In-class Time }\end{array}$ \\
\hline $\begin{array}{l}\text { Grade } \\
\text { reciprocity }\end{array}$ & $\begin{array}{l}\text { Establishes team agreement in } \\
\text { terms of target grade. }\end{array}$ & $\begin{array}{l}\text { Direct grade impact based on } \\
\text { individual performance. }\end{array}$ & $\begin{array}{l}\text { Provides for instructor } \\
\text { observation. }\end{array}$ \\
\hline Social loafing & Penalties are clearly documented. & $\begin{array}{l}\text { Direct link between performance } \\
\text { and grade. }\end{array}$ & $\begin{array}{l}\text { Instructor observation and } \\
\text { indirect positive influence. }\end{array}$ \\
\hline $\begin{array}{l}\text { Scheduling } \\
\text { challenges }\end{array}$ & $\begin{array}{l}\text { Deadlines for individual } \\
\text { contributions are clearly defined. }\end{array}$ & $\begin{array}{l}\text { Influence on expected student } \\
\text { flexibility. }\end{array}$ & $\begin{array}{l}\text { Reduction of outside classroom } \\
\text { meeting requirements. }\end{array}$ \\
\hline $\begin{array}{l}\text { Disconnect } \\
\text { between work } \\
\text { and school teams }\end{array}$ & & & $\begin{array}{l}\text { Allows for ongoing instructor } \\
\text { input on association of } \\
\text { educational and work setting. }\end{array}$ \\
\hline $\begin{array}{l}\text { Inefficiency of } \\
\text { teams }\end{array}$ & $\begin{array}{l}\text { Improves team function through } \\
\text { procedural guidelines. } \\
\text { Clarity of team and individual } \\
\text { expectations. }\end{array}$ & $\begin{array}{l}\text { Improved individual effort and } \\
\text { accountability. }\end{array}$ & Offsets homework requirements. \\
\hline $\begin{array}{l}\text { Conflicting } \\
\text { assignment } \\
\text { outcomes and } \\
\text { objectives }\end{array}$ & $\begin{array}{l}\text { The charter requires consensus } \\
\text { and endorsement by all team } \\
\text { members. }\end{array}$ & & $\begin{array}{l}\text { Instructor observation and } \\
\text { identification of potential } \\
\text { problems. } \\
\text { Real time assignment } \\
\text { adjustment. }\end{array}$ \\
\hline
\end{tabular}

It is clear that students' have a strong opinion regarding team-based assignments. Instructors that integrate these class requirements must carefully monitor the process to improve team success. Upfront acknowledgement of both the positive and negative aspects of team-based assignments and the strategies employed to improve the team learning experience should address the many of the student voices presented in this paper and establish a common starting point for improving student team experiences. 


\section{AUTHOR INFORMATION}

Jennifer L. Schultz is an assistant professor for Human Resource Management (HRM) in the College of Management at Metropolitan State University in Minneapolis, Minnesota. She serves as the Curriculum Coordinator for the undergraduate HRM program and teaches graduate and undergraduate courses in management and HRM.

Joel R. Wilson is an assistant professor in the College of Management at Metropolitan State University in Minneapolis, Minnesota.

Kenneth C. Hess is an assistant professor in the College of Management at Metropolitan State University in Minneapolis, Minnesota.

\section{REFERENCES}

1. Bormann Young, C., \& Henquinet, J. A. (2000, September/October). A conceptual framework for designing group projects. Journal of Education for Business, 56-60.

2. Hansen, R. S. (2006). Benefits and problems with student teams: Suggestions for improving team projects. Journal of Education for Business, 82(1), 11-19.

3. Johnson, D. W., \& Johnson, R. (1989). Cooperation and competition: Theory and research. Edina, MN: Interaction Book Company.

4. Katzenbach, J. R. \& Smith, D. K. (1993). The discipline of teams: What makes the difference between a team that performs and one that doesn't? Harvard Business Review, 111-120.

5. Slavin, R. (1983). Cooperative learning. New York: Longman.

6. Slavin, R. E. (1990). Research on cooperative learning: Consensus and controversy. Educational Leadership, 47(4), 52-54. 